REVIEW

\title{
Septic Cavernous Sinus Thrombosis: Case Report and Review of the Literature
}

\author{
Dinushi Weerasinghe and Christian J. Lueck \\ Department of Neurology, The Canberra Hospital and Australian National University Medical School, Canberra, Australia
}

\section{ABSTRACT}

Septic cavernous sinus thrombosis is a rare but serious complication of infection of the cavernous sinuses. There are no randomised, controlled trials of management of this condition and existing reviews of the literature are somewhat dated. The authors report a case with a favourable outcome and then present the findings of a literature review of the management of this condition. Outcome data suggest that corticosteroids are of equivocal benefit whereas antibiotics and anticoagulation are beneficial.

\section{ARTICLE HISTORY}

Received 6 August 2016

Revised 25 August 2016

Accepted 25 August 2016

\section{KEYWORDS}

Cavernous sinus thrombosis; infection; treatment

\section{Introduction}

Septic cavernous sinus thrombosis is a rare but serious complication of infection of the cavernous sinuses. In the pre-antibiotic era, it was associated with high mortality rates. ${ }^{1}$ With the introduction and widespread use of antibiotics, the outlook of this condition has improved somewhat, but this continues to depend on timely diagnosis and initiation of appropriate treatment. Potential therapies include antibiotics, corticosteroids, and anticoagulation, as well as surgical intervention for source control of the infection. ${ }^{2}$ Unfortunately, there are no randomised controlled trials of any of these treatments in this condition, and so management remains somewhat ad hoc.

A number of factors need to be considered when managing these patients. These include the source of infection (if known), the likely causative organism(s) and therefore the most appropriate choice of antibiotics, the presence of any underlying medical condition (s), and whether or not surgical treatment is appropriate. We report the case of a patient with septic cavernous sinus thrombosis who eventually had a favourable outcome. We then report a review of the existing literature regarding treatment of this condition.

\section{Case history}

A 41-year-old man of Indian origin presented to a tertiary-care centre with a 1-day history of fever, headache, and bilateral periorbital and mid-facial swelling. The day prior to the onset of his symptoms, he had attempted to burst a furuncle in the inner margin of his right nostril. He had no relevant medical history and was not on any medications. He had last travelled to India 4 months earlier.

On examination, he was conscious and alert, but was febrile $\left(38.1^{\circ} \mathrm{C}\right)$. He had marked facial and periorbital swelling with bilateral blepharoptosis, chemosis, and proptosis. His cardiovascular and respiratory examination was normal, and there were no other neurological deficits.

On neuro-ophthalmological examination, he had a visual acuity of $6 / 12$ bilaterally. There were no visual field defects to confrontation. Colour vision was normal, there was no relative afferent pupillary defect, and the intraocular pressures were normal. On funduscopy, there was no evidence of optic disc swelling. He had a full range of eye movements but complained of pain on moving his eyes. The conclusion was that there was no clinical evidence of optic nerve compression.

At presentation, blood cultures were taken along with swabs from the nasal furuncle. His inflammatory markers were markedly raised (white cell count $16 \times$ $10^{9} / \mathrm{L}$, erythrocyte sedimentation rate $67 \mathrm{~mm} / \mathrm{h}$, C-reactive protein $325 \mathrm{mg} / \mathrm{L}$ ), with normal renal functions and slightly deranged liver functions tests (total bilirubin $28 \mu \mathrm{mol} / \mathrm{L}$, alkaline phosphatase $177 \mathrm{U} / \mathrm{L}, \gamma-$ 


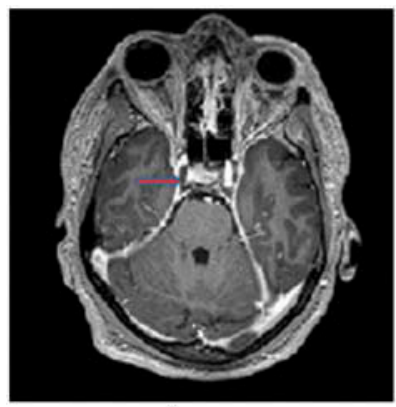

A

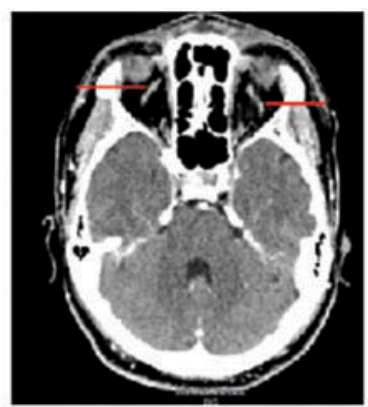

B

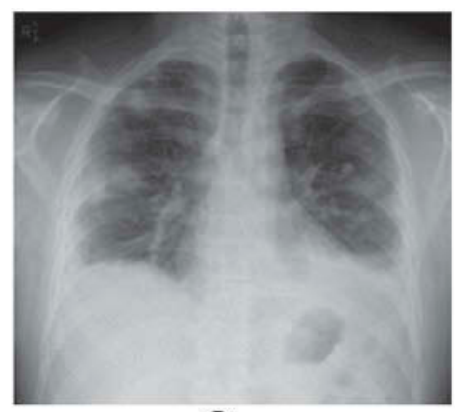

C

Figure 1. (A) Brain MRI (T1-weighted with gadolinium) showing non- opacification of the right cavernous sinus. (B) Contrastenhanced brain $\mathrm{CT}$ showing bilateral engorged thrombosed superior ophthalmic veins. (C) Chest $\mathrm{X}$ ray showing multiple opacities in the lungs and left-sided pleural effusion.

glutamyltransferase $177 \mathrm{U} / \mathrm{L})$. Tests for vasculitis, thrombophilia, human immunodeficiency virus (HIV), and diabetes were negative. Computed tomography (CT) brain (pre- and post-contrast with arteriogram and venogram) and magnetic resonance imaging (MRI)/MR venogram revealed engorged, thrombosed superior ophthalmic veins bilaterally with non-opacification of the cavernous sinuses, consistent with bilateral cavernous sinus thrombosis (Figure $1 \mathrm{~A}$ and $\mathrm{B}$ ).

Pending blood cultures, he was treated empirically with high-dose intravenous (IV) flucloxacillin and ceftriaxone, and was anticoagulated with enoxaparin. He was not treated with corticosteroids. Although his ophthalmological symptoms improved on the above regimen and his peri-orbital swelling subsided, 1 week after admission, he developed a cough, shortness of breath, and reduced $\mathrm{O}_{2}$ saturation. He was transferred to the intensive care unit (ICU) at this stage. A chest $\mathrm{X}$-ray revealed bilateral, multilobar consolidation with a left-sided pleural effusion (Figure 1C). Multiple blood cultures as well as cultures taken from the nasal furuncle grew methicillin-sensitive Staphylococcus aureus (MSSA). There was a suggestion on his echocardiogram of possible tricuspid valve vegetations. Unfortunately, he continued to deteriorate with worsening respiratory distress and was intubated. His antibiotics were changed to meropenem and linezolid because of a suspicion of a hospitalacquired pneumonia. Following this he began to improve, and his symptoms resolved over the next 2 weeks. He was discharged 1 month later on warfarin, the plan being to discontinue this after 3 months if a follow-up CT venogram showed resolution of the thromboses. Intravenous flucloxacillin was continued for 6 weeks, followed by oral dicloxacillin. He ultimately made a full recovery.

\section{Comment}

The sequence of events that led to the admission to the ICU was felt to be as follows: venous blood carried the MSSA from his nose to his cavernous sinuses, resulting in septic cavernous sinus thrombosis. Haematogenous spread of the infection, either directly from the furuncle or from the cavernous sinuses seeded vegetations on the tricuspid valve, which, in turn, caused a shower of septic emboli to his lungs and multilobar consolidation. There was a suspicion of a hospital-acquired pneumonia complicating the above situation given the suboptimal response to the initial antibiotics. During the management of his illness, we became aware of the lack of evidence on which to base decisions regarding the use of corticosteroids and whether or not he should be anticoagulated.

\section{Materials and methods}

A literature search was carried out looking for all relevant articles published in English between January 1980 and July 2015. 1980 was chosen because imaging (CT or MRI) was more likely to be involved in making the diagnosis. The databases searched were PubMed, Embase, MEDLINE, CINAHL (EBSCO), Health \& Medical Complete (ProQuest), and Health Management (ProQuest). The keywords used were 
"septic", "cavernous sinus thromboses", "infection", "adult", "treatment", and "management".

Data extracted for each case included age, gender, source of infection, organism(s), co-morbidities, imaging modality used, details of any surgery performed, use of antibiotics, corticosteroids, use of anticoagulation, and outcome.

\section{Results}

The initial search yielded 133 articles. Paediatric cases (age $<16$ years) and cases of post-traumatic cavernous sinus thrombosis (CST), post-surgical CST, and CST associated with widespread cerebral venous sinus thrombosis secondary to causes such as thrombophilia were excluded. Articles reporting imaging without clinical details or clinical diagnosis without imaging confirmation were also excluded. Ultimately, 68 relevant articles were identified and all were retrieved. These included four literature reviews $(1986,1988$, 1988 , and 2002) ${ }^{1-4}$ and 64 other articles ${ }^{5-68}$ containing a total of 88 case reports. In the early reports from the 1980s, the diagnosis was confirmed angiographically in some patients, but most patients were diagnosed clinically and/or through post-mortem studies. ${ }^{1}$

Of the 88 reported cases, two thirds (58 cases) were male and one third (30 cases) were female. Ages ranged from 16 to 79 years. Thirty patients (34\%) had prior medical conditions that could have resulted in immunosuppression such as diabetes, chronic alcohol abuse, long-term corticosteroid use, and bone marrow transplant. Details of individual cases are provided in Table 1.

\section{Source of infection}

Not surprisingly, infections arose from anatomical sites known to drain to the cavernous sinuses. The commonest source was spread from paranasal sinusitis, accounting for $57 \%$ of patients. This included spread from maxillary, ethmoidal, and sphenoidal sinuses, with the sphenoidal sinus being the most common. Mid-facial infections (as in our patient) and dental infections were responsible for 12 and 11 cases, respectively. Incision and drainage of nasal and other facial abscesses by "untrained hands" preceded most of these cases. Otitis media and spread from distant sites (intravenous drug use, myiasis of the eyelid, and anorectal abscess) were responsible for 3 cases each. The source was not known or not reported in 9 cases.

\section{Causative organisms}

Both bacteria and fungi were implicated (Table 2). Although blood cultures were routinely performed, isolating an organism was not always successful, often because antibiotics had been administered prior to obtaining the blood cultures and the fastidious nature of the organism involved. The commonest reported organism was methicillin-resistant Staphylococcus aureus (MRSA), followed by MSSA. Various streptococci, other staphylococci, oral anaerobic flora, and gram-negative organisms were also reported. Aspergillus fumigatus was the commonest fungal infection. Fungal infections were more commonly reported in immunocompromised patients, including patients with diabetes mellitus, connective tissue disorders, haematological malignancies, those treated with immunosuppressants, or patients who had had a bone marrow transplant. Prognosis was poor in this immunocompromised patient population irrespective of the organism, but more so when the organism was a fungus.

\section{Imaging}

The commonest imaging modality was MRI (42\%), followed by contrast-enhanced CT brain (23\%). The choice of modality mostly reflected the availability in different centres. In 7 case reports, the imaging modality was not mentioned, although confirmation of CST was apparently obtained through imaging.

\section{Antibiotic use}

The choice of antibiotic or antifungal depended on the organism isolated. Almost all major groups of antibiotics were used (Table 3). The commonest empirically used antibiotics were flucloxacillin, vancomycin, and third-generation cephalosporins. In most case studies, antibiotics were changed once an organism had been isolated, the eventual choice depending somewhat on local antibiotic guidelines and availability. Amphotericin B was the commonest antifungal 


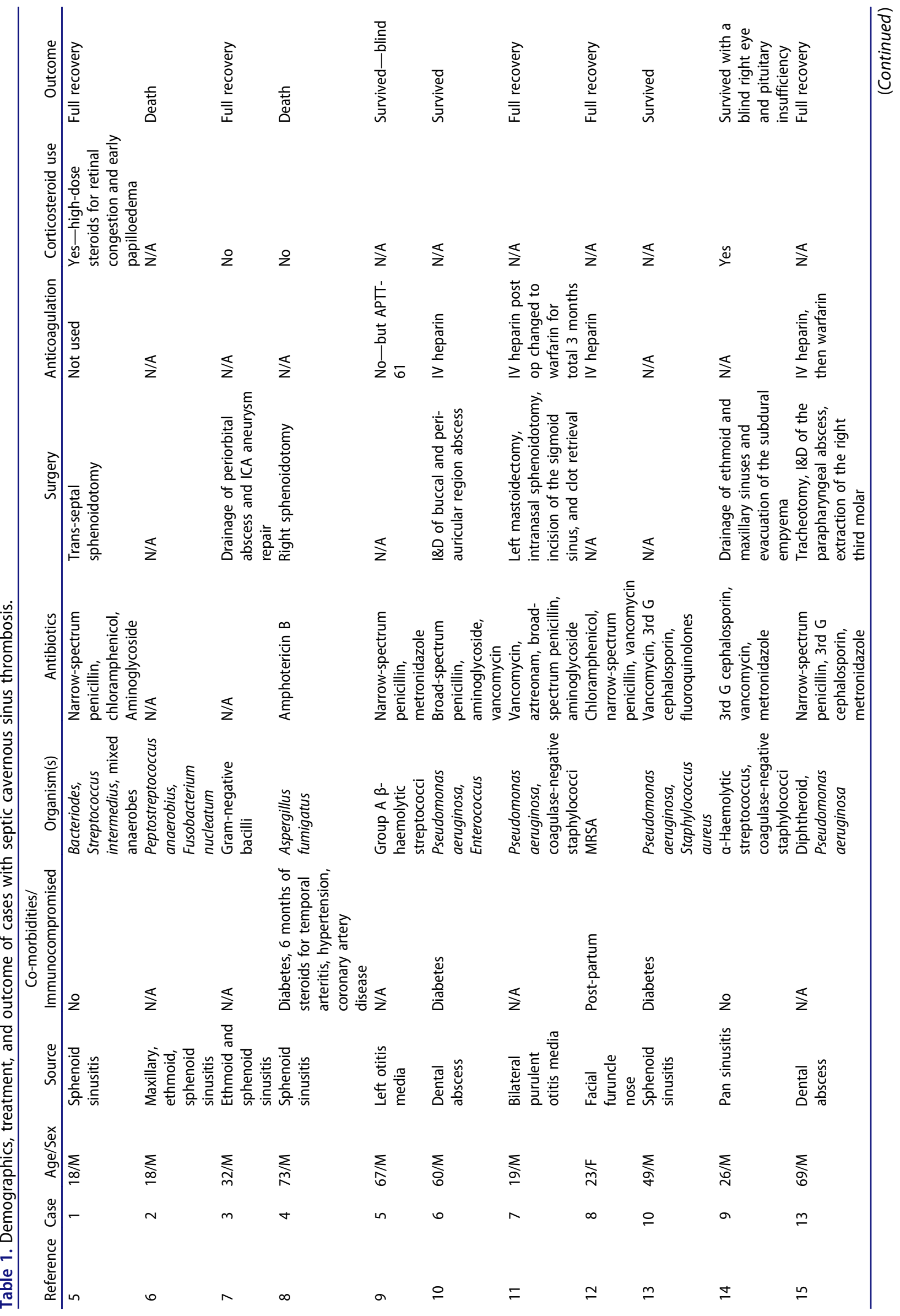


NEURO-OPHTHALMOLOGY

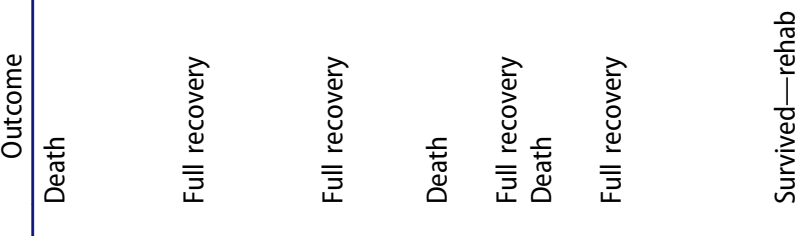

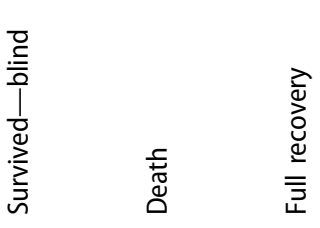
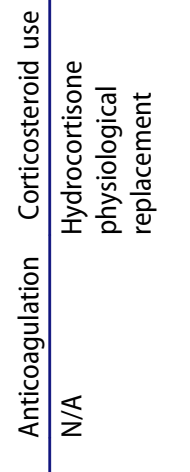

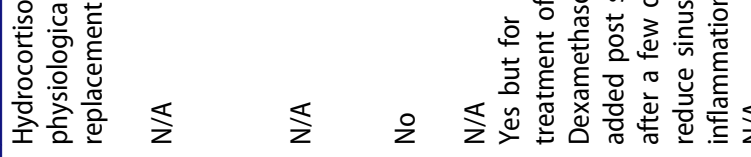

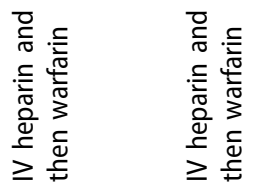

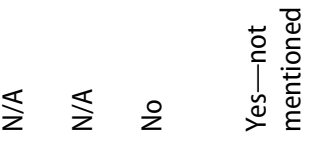

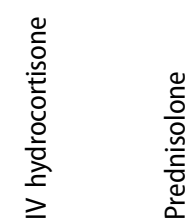

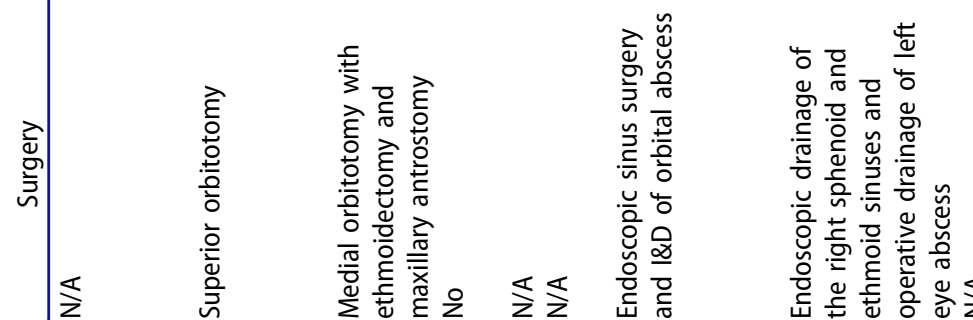

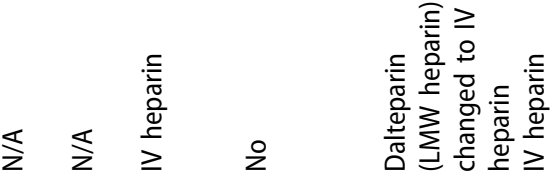

$\Sigma$

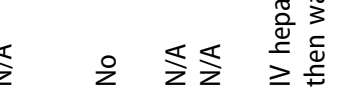

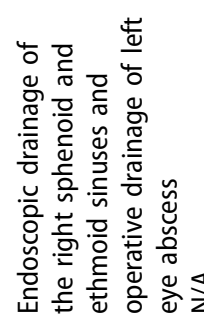

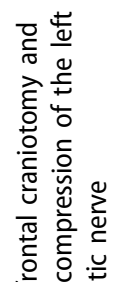

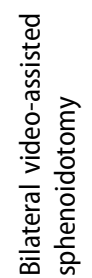

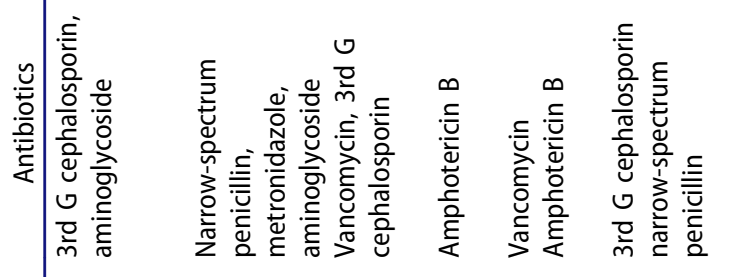

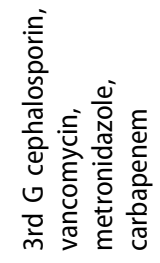

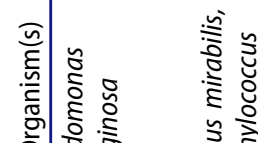

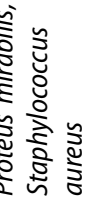

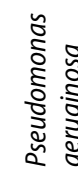
縍

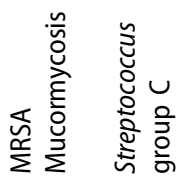

产

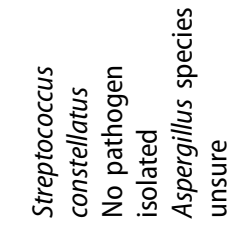

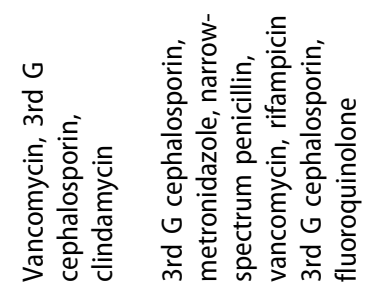

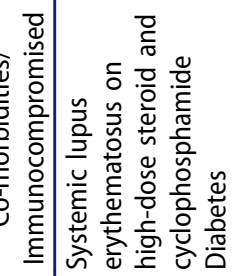

岃

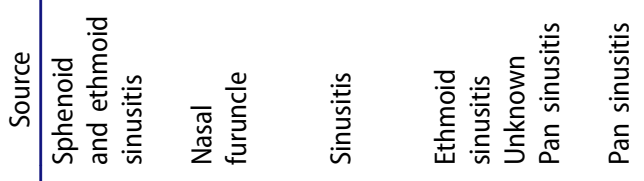

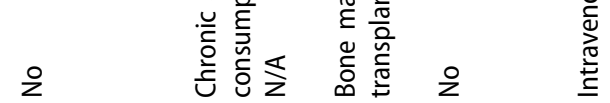

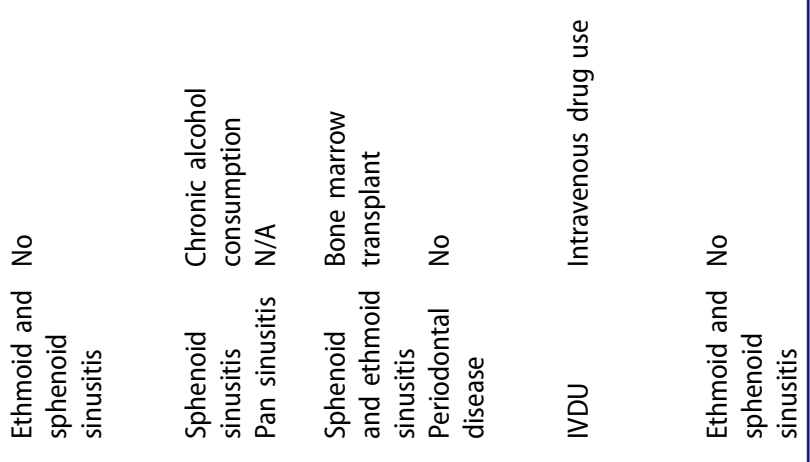

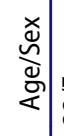

(2)

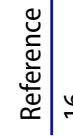

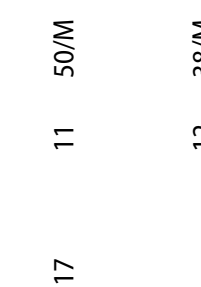

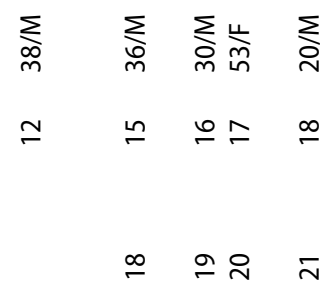

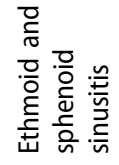

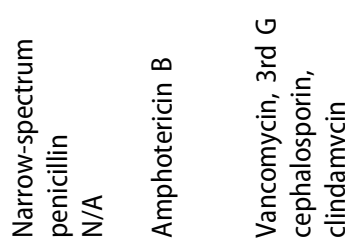

है

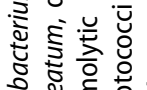

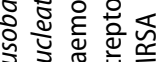

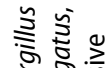

这产. 


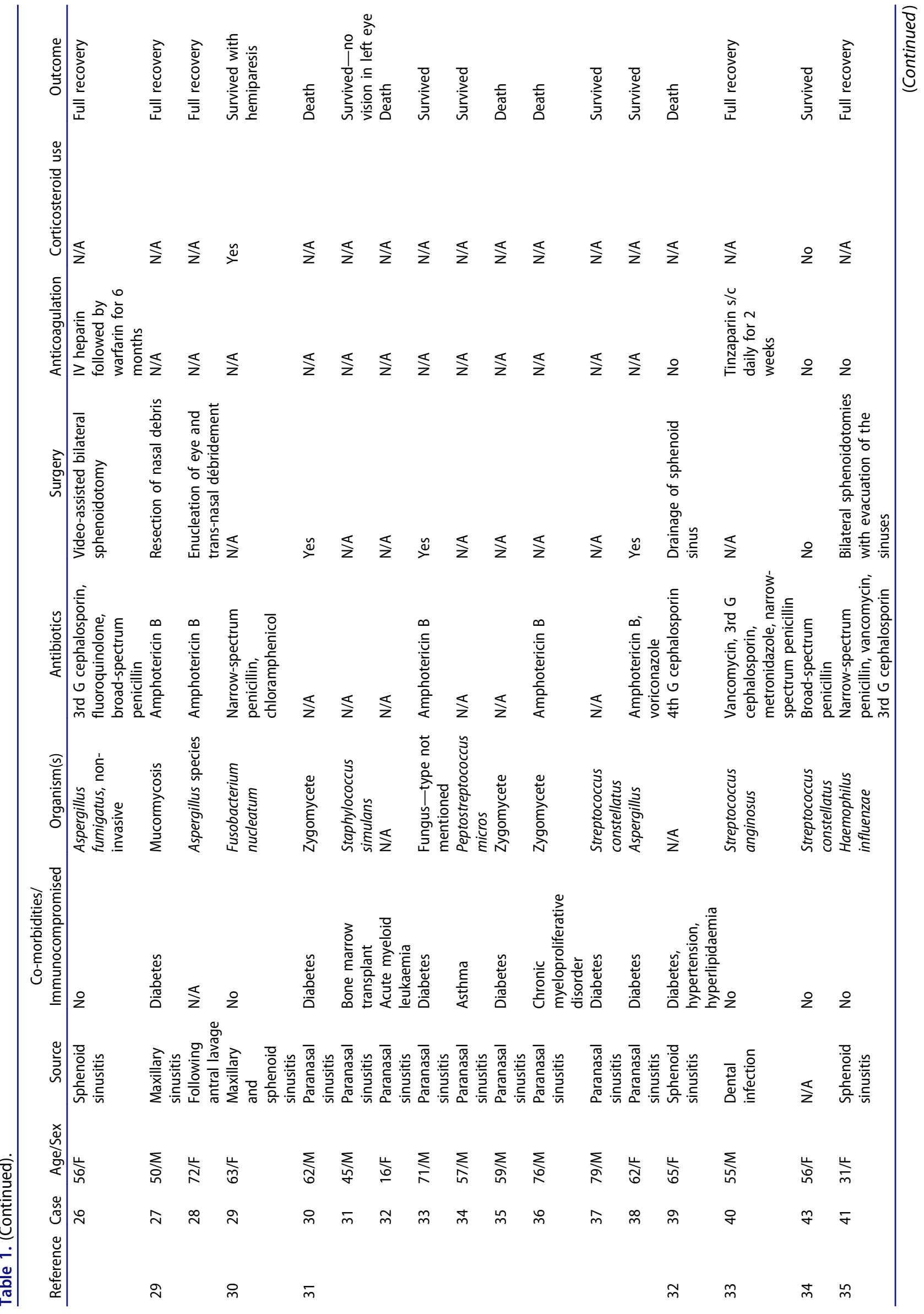


NEURO-OPHTHALMOLOGY $\Leftrightarrow 269$

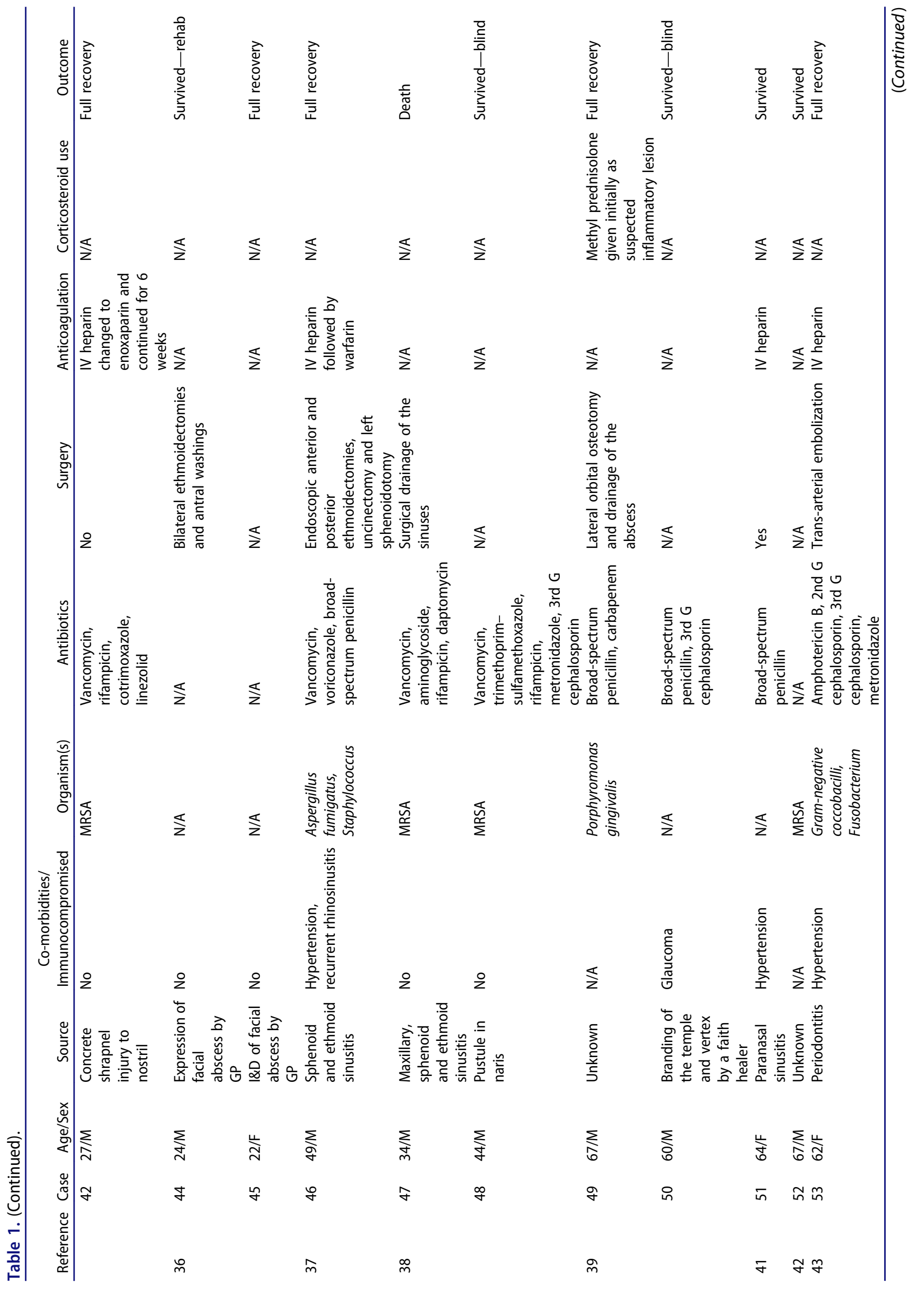




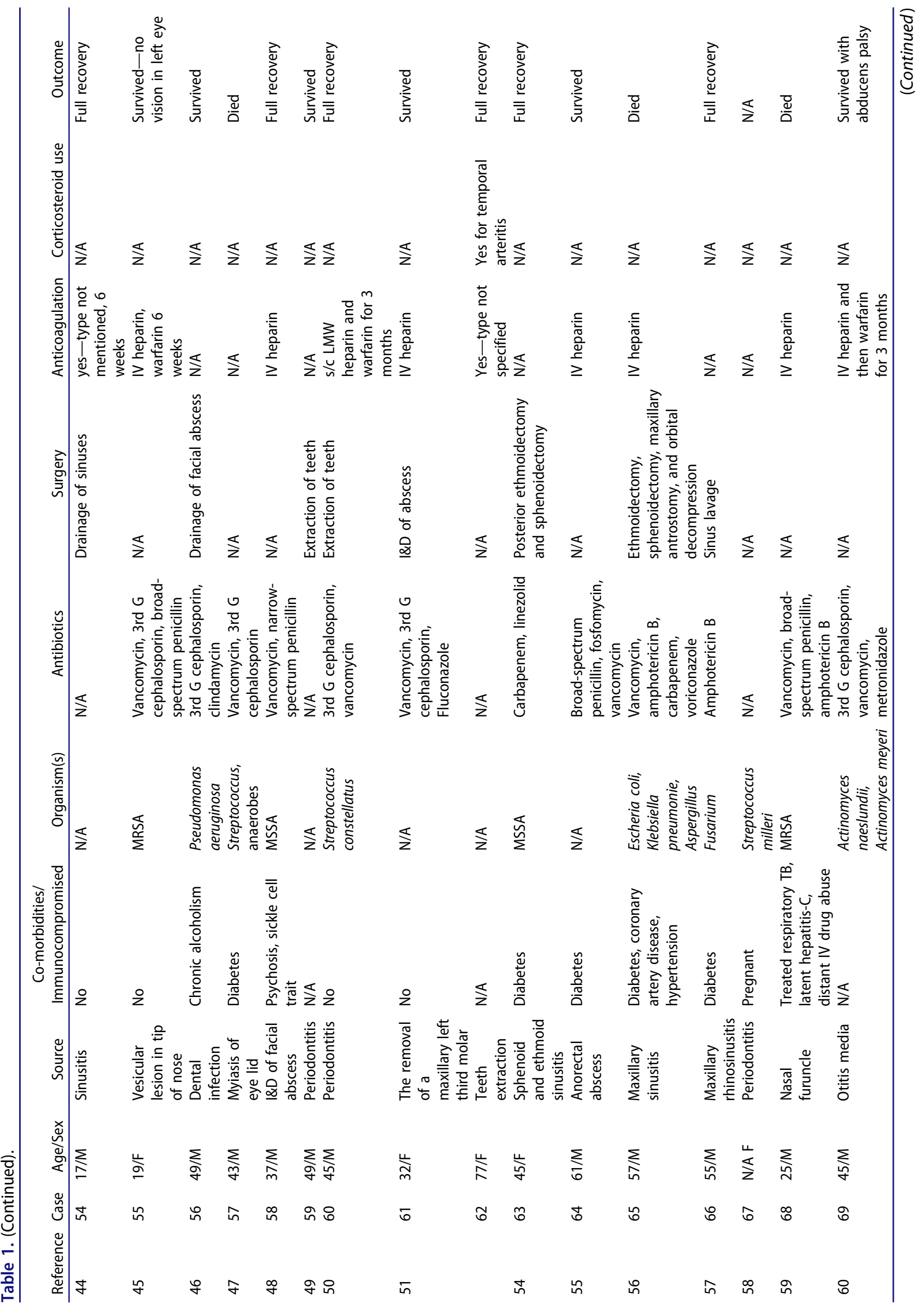




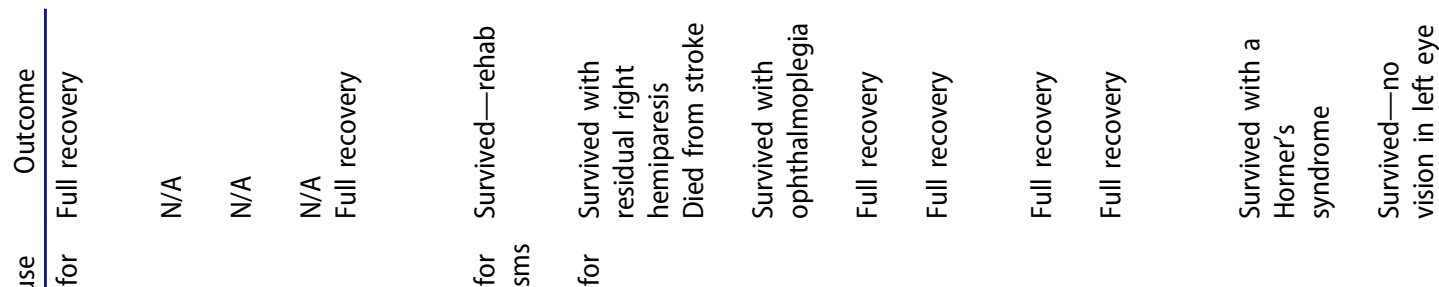

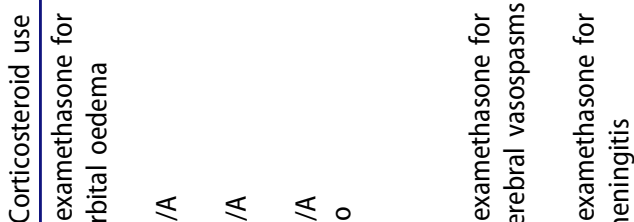

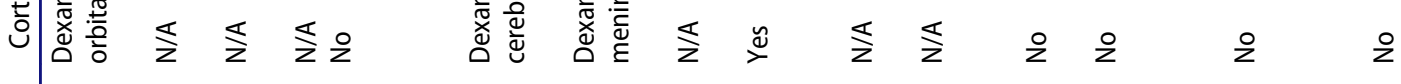

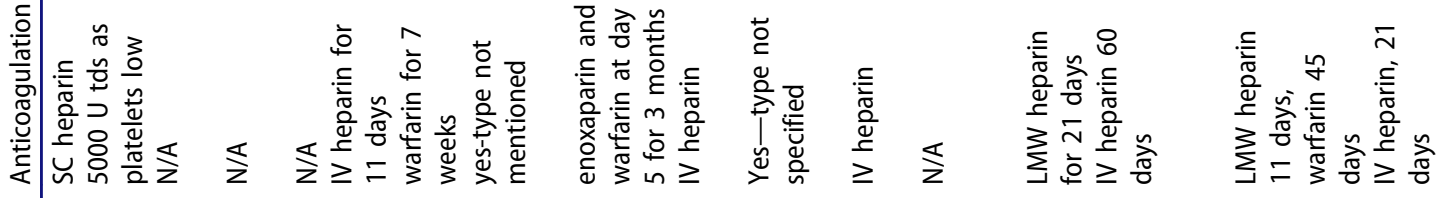

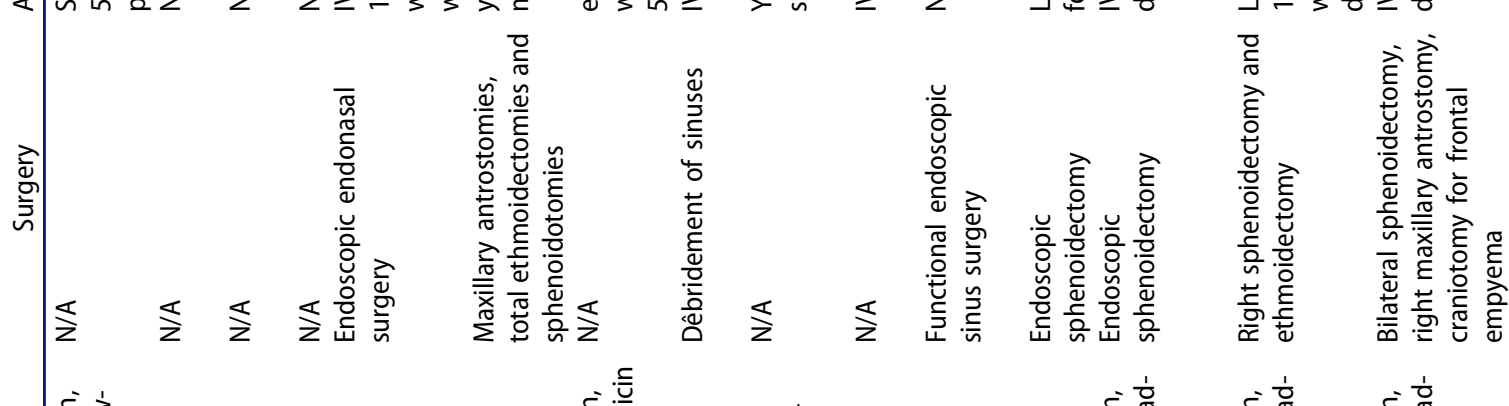

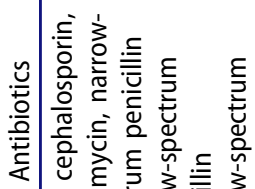

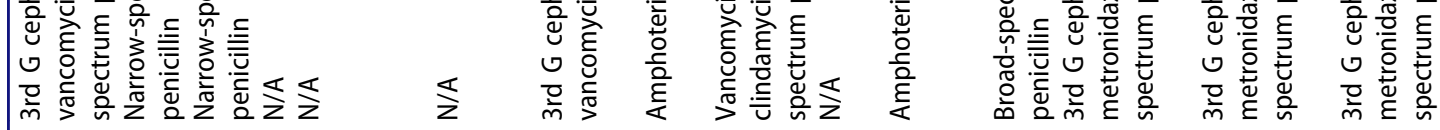

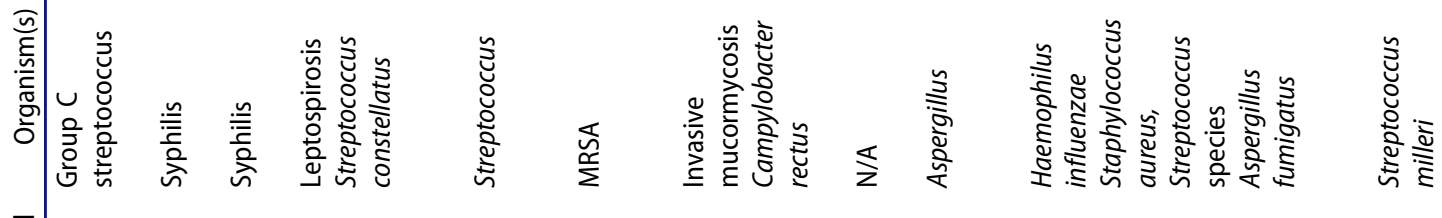

:

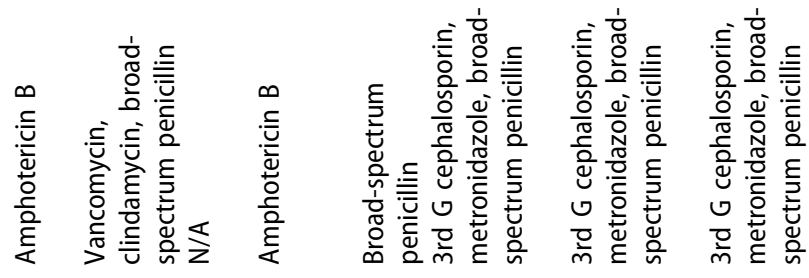

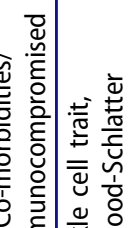

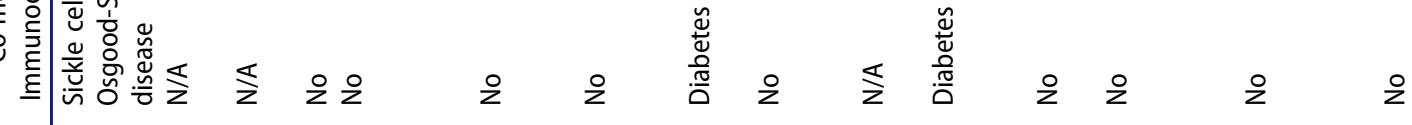

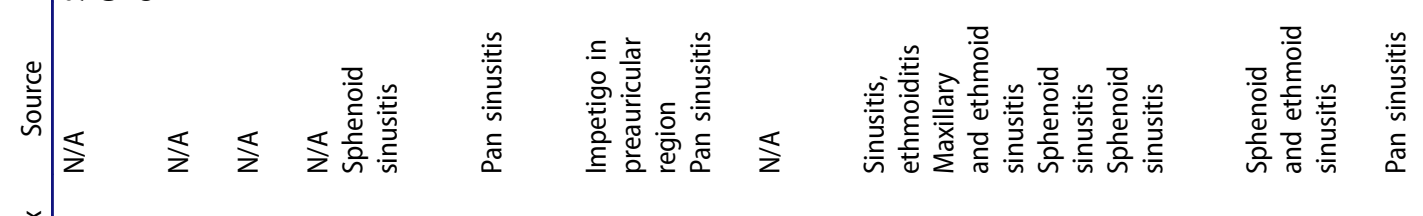

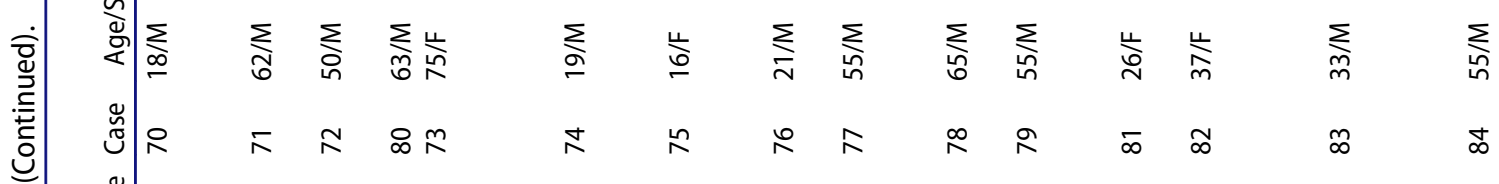

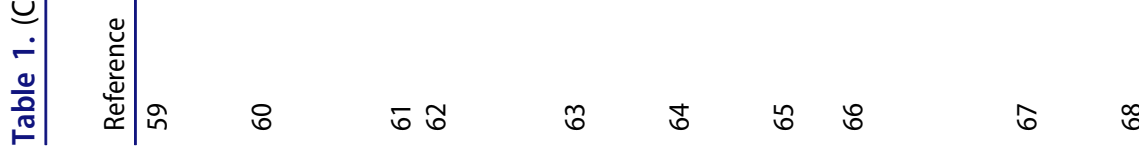




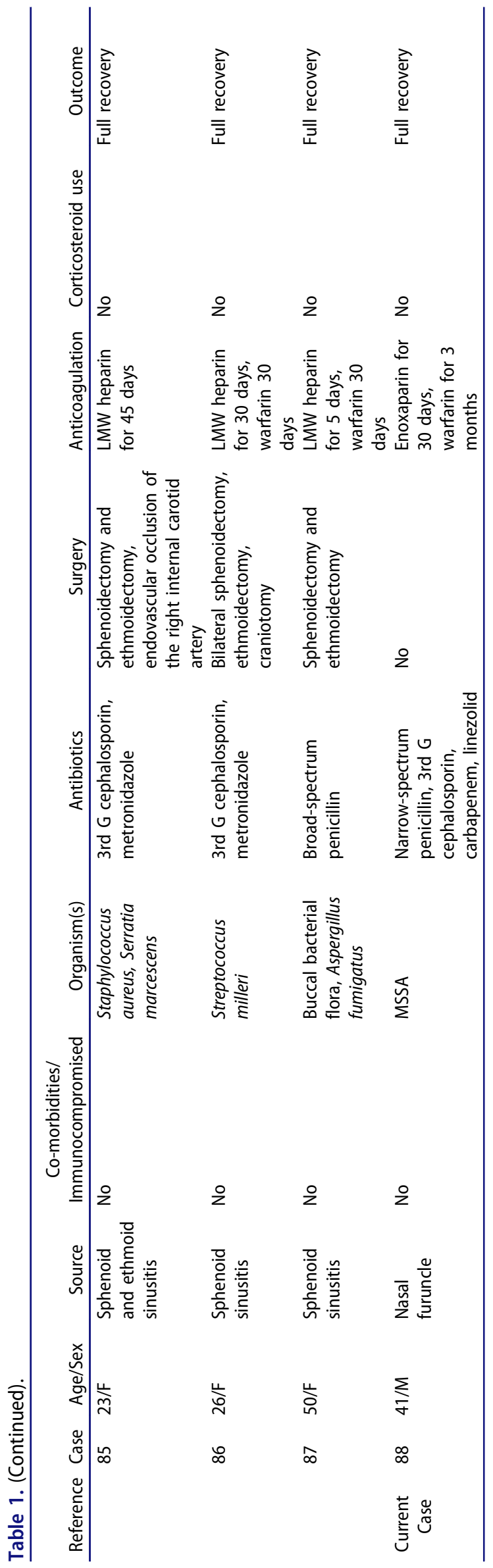


Table 2. Organisms isolated from patients with cavernous sinus thrombosis.

\begin{tabular}{|c|c|c|}
\hline Organism & Number & Percentage \\
\hline \multicolumn{3}{|l|}{ Gram-positive cocci } \\
\hline \multicolumn{3}{|l|}{ Coagulase-positive Staphylococcus } \\
\hline - Methicillin-resistant Staphylococcus aureus & 11 & 13 \\
\hline - Methicillin-sensitive Staphylococcus aureus & 5 & 6 \\
\hline Coagulase-negative Staphylococcus & 3 & 3 \\
\hline - Staphylococcus simulans & 1 & 1 \\
\hline \multicolumn{3}{|l|}{ Streptococcus } \\
\hline - a-Haemolytic streptococci & 1 & 1 \\
\hline - $\beta$-Haemolytic streptococci & 2 & 2 \\
\hline Group C streptococcus & 2 & 2 \\
\hline Enterococcus & 1 & 1 \\
\hline \multicolumn{3}{|l|}{ Group F streptococcus } \\
\hline - Streptococcus milleri & 4 & 5 \\
\hline - Streptococcus constellatus & 5 & 6 \\
\hline - Streptococcus anginosus & 1 & 1 \\
\hline \multicolumn{3}{|l|}{ Peptostreptococcus } \\
\hline - Peptostreptococcus anaerobius & 4 & 5 \\
\hline - Peptostreptococcus micros & 4 & 5 \\
\hline \multicolumn{3}{|l|}{ Gram-negative bacilli } \\
\hline - Pseudomonas aeruginosa & 7 & 8 \\
\hline - Fusobacterium nucleatum & 4 & 5 \\
\hline • Haemophilus influenzae & 3 & 3 \\
\hline - Campylobacter rectus & 1 & 1 \\
\hline - Proteus mirabilis & 1 & 1 \\
\hline - Klebsiella pneumoniae & 1 & 1 \\
\hline - Serratia marcescens & 1 & 1 \\
\hline • Escherichia coli & 1 & 1 \\
\hline \multicolumn{3}{|l|}{ Gram-positive bacilli } \\
\hline - Actinomyces naeslundii and meyeri & 1 & 1 \\
\hline \multicolumn{3}{|l|}{ Spirochaetes } \\
\hline - Treponema pallidum & 2 & 2 \\
\hline - Leptospira & 1 & 1 \\
\hline \multicolumn{3}{|l|}{ Fungi } \\
\hline - Aspergillus fumigatus & 10 & 11 \\
\hline - Zygomycetes & 4 & 5 \\
\hline - Mucorales & 3 & 3 \\
\hline • Fusarium & 1 & 1 \\
\hline Not available & 13 & 15 \\
\hline
\end{tabular}

used. Most reports did not mention the duration of antibiotic use, but prolonged courses were commonly reported if seeding of other organs (such as cardiac valves or long bones) was suspected, with fungal infection, and in immunocompromised hosts.

\section{Surgery}

A surgical procedure was performed in 54\% of patients. These were mostly on the paranasal sinuses to address the source of infection (e.g., ethmoidectomy, sphenoidectomy, maxillary antrostomy, etc.). Other procedures performed included incision and drainage of abscesses, dental extractions, craniotomy for evacuation of subdural empyaema, and orbital decompression. One patient underwent an incision of the sigmoid sinus and clot retrieval with subsequent full recovery.

\section{Corticosteroids and anticoagulation}

In the previous four reviews, ${ }^{1-4}$ the authors attempted to address these issues but evidence was conflicting. Southwick et al. ${ }^{1}$ looked at case reports of patients from 1940 to 1984 and concluded that mortality was lower among patients who received heparin treatment. They also concluded that corticosteroids might have a place in reducing cranial nerve dysfunction and orbital congestion. Levine et al. $^{3}$ found no conclusive evidence that anticoagulation reduced mortality, although there was a non-significant trend towards benefit and there was evidence suggesting reduced residual morbidity when used early in combination with antibiotics. They did not evaluate corticosteroid use.

Of the 88 cases in our review, 15 patients received corticosteroids, but there were various reasons cited. Five patients received corticosteroids to reduce inflammation in cranial and orbital structures, one received "replacement doses" and the others received

Table 3. Antibiotics used in treating cavernous sinus thrombosis.

\begin{tabular}{|c|c|c|c|}
\hline Class & Antibiotic & Number & Percentage \\
\hline Beta-lactams & $\begin{array}{l}\text { Nafcillin, amoxicillin/clavulanate, crystalline penicillin, flucloxacillin, meropenem, ticarcillin, aztreonam } \\
\text { ampicillin/sulbactam, imipenem, piperacillin/tazobactam }\end{array}$ & 37 & 43 \\
\hline Aminoglycosides & Gentamicin, tobramycin, netromycin & 5 & 6 \\
\hline Cephalosporins & Cefotaxime, ceftriaxone, ceftazidime, cefpirome, cefuroxime & 31 & 36 \\
\hline Fluoroquinolones & Ofloxacin & 3 & 3 \\
\hline Rifamycins & Rifampicin & 5 & 6 \\
\hline Miscellaneous & $\begin{array}{l}\text { Chloramphenicol, metronidazole, co-trimoxazole, linezolid, daptomycin, clindamycin, fosfomycin, } \\
\text { vancomycin }\end{array}$ & 54 & 62 \\
\hline Antifungals & Amphotericin B, voriconazole, fluconazole & 19 & 22 \\
\hline
\end{tabular}

Note. Totals add up to more than $100 \%$ because some cases were treated with multiple antibiotics. 


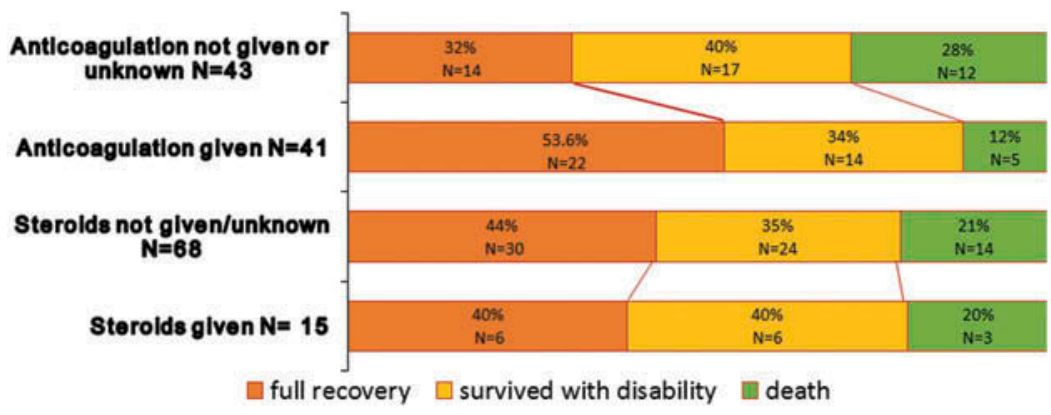

Figure 2. Patient outcome following use of steroids and anticoagulation.

corticosteroids for other indications such as treatment of concomitant systemic lupus erythematosus, meningitis, as part of a bone marrow transplant protocol, or an initial (incorrect) working diagnosis of temporal arteritis. The remainder of the patients either did not receive corticosteroids or their use was not mentioned. When comparing patients who were given corticosteroids with patients who were not given or status unknown, approximately equal percentages made a full recovery ( $40 \%$ vs. $44 \%$ ), survived with disability ( $40 \%$ vs. $35 \%$ ), or died ( $20 \%$ vs. $21 \%$ ), suggesting that there was no clear overall benefit from corticosteroid use.

Anticoagulation was mentioned in the management in 41 out of 88 patients; of the remainder, one half were not treated with anticoagulants whereas their use was not mentioned in the other half. The anticoagulant most commonly used was heparin, followed by warfarin, but a few cases were treated with tinzaparin, enoxaparin, and daltaparin, and the exact agent was not specified in a few other cases. The duration of therapy was also variable, generally ranging from 2 to 6 weeks, but 5 patients received therapy for 3 months or more. Compared with patients who were not anticoagulated, a considerably greater number of anticoagulated patients made a full recovery (53.6\% vs. $32 \%)$ and fewer patients died (12\% vs. $28 \%$ ) (see Figure 2). However, there was no clear difference in morbidity, with almost equal proportions of patients surviving with disability in each group (34\% vs. $40 \%)$.

\section{Discussion}

Our literature review identified only 88 case reports of infective cavernous sinus thrombosis in the literature over a period of 25 years providing class IV evidence for the management of septic cavernous sinus thrombosis. We acknowledge the limitations associated with a retrospective review of cases such as lack of standardised reporting across cases and the inability to control for and measure other variables that likely impacted outcomes (i.e., age, level of disability, premorbid health status, delays to treatment, etc.). There was a strong suggestion of reporting bias, with a tendency to report cases with better outcomes. Antibiotics were undoubtedly beneficial, although empirical use was variable and the ultimate choice was dependent on which organism was eventually isolated. Surgery was used for treatment of the source of infection rather than the cavernous sinus infection/ thrombosis per se. There was no signal that corticosteroids were beneficial, although they might be required for other reasons. There was a strong suggestion that anticoagulation improved mortality, although there did not seem to be any benefit to morbidity. Unfortunately, evidence regarding how long to continue anticoagulation was lacking. It is clear that further studies are needed to determine the optimal therapy for this condition. These are likely to be multicentre studies in view of the rarity of the disease.

\section{Declaration of interest}

The authors report no conflicts of interest. The authors alone are responsible for the content and writing of the article.

\section{References}

[1] Southwick FS, Richardson EP Jr, Swartz MN. Septic thrombosis of the dural venous sinuses. Medicine 1986;65:82-106.

[2] DiNubile MJ. Septic thrombosis of the cavernous sinuses. Arch Neurol 1988;45:567-572. 
[3] Levine SR, Twyman RE, Gilman S. The role of anticoagulation in cavernous sinus thrombosis. Neurology 1988;38:517-522.

[4] Bhatia K, Jones NS. Septic cavernous sinus thrombosis secondary to sinusitis: are anticoagulants indicated? A review of the literature. J Laryngol Otol 2002;116:667-676.

[5] Sofferman RA. Cavernous sinus thrombophlebitis secondary to sphenoid sinusitis. Laryngoscope 1983;93:797-800.

[6] Curnes JT, Creasy JL, Whaley RL, Scatliff JH. Air in the cavernous sinus: a new sign of septic cavernous sinus thrombosis. Am J Neuroradiol 1987;8:176-177.

[7] Endo S, Ohtsuji T, Osamu F, Oka N, Takaku A. A case of septic cavernous sinus thrombosis with sequential dynamic angiographic changes. A case report. Surg Neurol 1989;32:59-63.

[8] Dyken ME, Biller J, Yuh WTC, Fincbam R, Moore SA, Justin E. Carotid-cavernous sinus thrombosis caused by Aspergillus fumigatus: magnetic resonance imaging with pathologic correlation-a case report. Angiology 1990;41:652-657.

[9] Mackintosh HT. Septic cavernous sinus thrombosis. A case report. Aust N Z J Ophthalmol 1991;19:175-182.

[10] Wen-Der Yun M, Hwung CF, Hwang CE, Lui CC. Cavernous sinus thrombosis following odontogenic and cervicofacial infection. Eur Arch Oto-Rhino-Laryngol 1991;248:422-424.

[11] Doyle KJ, Jackler RK. Otogenic cavernous sinus thrombosis. Otolaryngol Head Neck Surg 1991;104:873-877.

[12] Hsu W-M, Lin C-H, Chen Y-R. Septic cavernous sinus thrombosis complicating facial furuncle. Case report. $J$ Surg Assoc Republic China 1995;28:215-219.

[13] Colson AE, Daily JP. Orbital apex syndrome and cavernous sinus thrombosis due to infection with Staphylococcus aureus and Pseudomonas aeruginosa. Clin Infect Dis 1999;29:701-702.

[14] Sahjpaul RL, Lee DH. Infratentorial subdural empyema, pituitary abscess, and septic cavernous sinus thrombophlebitis secondary to paranasal sinusitis: case report. Neurosurgery 1999;44:864-868.

[15] Feldman DP, Picerno NA, Porubsky ES. Cavernous sinus thrombosis complicating odontogenic parapharyngeal space neck abscess: a case report and discussion. Otolaryngol Head Neck Surg 2000;123:744-745.

[16] Chen Y-C, Cheng T-T, Lai H-M, Wu C-H. Overwhelming septic cavernous sinus thrombosis in a woman after combination of high-dose steroid and intravenous cyclophosphamide therapy for lupus nephritis. Lupus 2000;9:78-79.

[17] Suneetha N, Battu RR. Orbital abscess: management and outcome. Indian J Ophthalmol 2000;48:129-134.

[18] de Medeiros CR, Bleggi-Torres LF, Faoro LN, ReisFilho JS, Silva LC, de Medeiros BC, Loddo G, Pasquini R. Cavernous sinus thrombosis caused by zygomycosis after unrelated bone marrow transplantation. Transplant Infect Dis 2001;3:231-234.

[19] Snyder GM, Pothuru S. Cavernous sinus thrombosis associated with MRSA bacteremia. Am J Med Sci 2008;336:353.
[20] Mandava P, Chaljub G, Patterson K, Hollingsworth JW. MR imaging of cavernous sinus invasion by mucormycosis: a case study. Clin Neurol Neurosurg 2001;103:101-104.

[21] Migirov L, Eyal A, Kronenberg J. Treatment of cavernous sinus thrombosis. Isr Med Assoc J 2002;4:468-489.

[22] Watkins LM, Pasternack MS, Banks M, Kousoubris P, Rubin PAD. Bilateral cavernous sinus thromboses and intraorbital abscesses secondary to Streptococcus milleri. Ophthalmology 2003;110:569-574.

[23] Chang WN, Chen SD, Lui CC, Huang CC, Lu CH. Septic cavernous sinus thrombosis due to Streptococcus constellatus infection. J Formos Med Assoc 2003;102:733-736.

[24] Quisling SV, Mawn LA, Larson TC. Blindness associated with enlarging mycotic aneurysm after cavernous sinus thrombosis. Ophthalmology 2003;110:2036-2039.

[25] Gupta V, Keller A, Halliday W, Sanche S, Hassegawa W, Messner H, Kiss T, Lipton J. Cavernous sinus thrombosis presenting with diplopia in an allogeneic bone marrow transplant recipient. Am J Hematol 2004;77:77-81.

[26] Arat YO, Shetlar DJ, Rose JE, Tex H. Blindness from septic thrombophlebitis of the orbit and cavernous sinus caused by Fusobacterium nucleatum. Arch Ophthalmol 2004;122:652-654.

[27] Muhtaseb M, Marjanovic B, Waddilove L, Ionides A, Thompson GM. Cavernous sinus thrombosis secondary to MRSA septicaemia. Neuro-ophthalmology 2004;28:245-250.

[28] Devèze A, Facon F, Latil G, Moulin G, Payan-Cassin $\mathrm{GH}$, Dessi P. Cavernous sinus thrombosis secondary to noninvasive sphenoid aspergillosis. Rhinology 2004;43:152-155.

[29] Munjal M, Khurana AS. Fungal infections and cavernous sinus thrombosis. Indian J Otolaryngol Head Neck Surg 2004;56:235-237.

[30] Chang CS, Liou CW, Lui CC, Chang KC, Huang CC. Cavernous sinus thrombosis and cerebral infarction caused by Fusobacterium nucleatum infection. Chang Gung Med J 2004;27:459-463.

[31] Chen HW, Su CP, Su DH, Chen HW, Chen YC. Septic cavernous sinus thrombosis: an unusual and fatal disease. J Formos Med Assoc 2006;105:203-209.

[32] Kamouchi M, Wakugawa Y, Okada Y, Kishikawa K, Matsuo R, Toyoda K, Yasumori K, Inoue T, Ibayashi S, Iida M. Venous infarction secondary to septic cavernous sinus thrombosis. Intern Med 2006;45:25-27.

[33] Pavlovich P, Looi A, Rootman J. Septic thrombosis of the cavernous sinus: two different mechanisms. Orbit 2006;25:39-43.

[34] Hoshino C, Satoh N, Sugawara S, Kuriyama C, Kikuchi A, Ohta M. Septic cavernous sinus thrombosis complicated by narrowing of the internal carotid artery, subarachnoid abscess and multiple pulmonary septic emboli. Intern Med 2007;46:317-323.

[35] Munckhof WJ, Krishnan A, Kruger P, Looke D. Cavernous sinus thrombosis and meningitis from community-acquired methicillin-resistant Staphylococcus aureus infection. Intern Med J 2008;38:283-287. 
[36] de Lange LJ, Magazi DS. Cavernous sinus thrombosis-a possible lethal complication of facial abscess manipulation. S Afr Med J 2009;99:616.

[37] Cheung EJ, Scurry WC, Isaacson JE, McGinn JD. Cavernous sinus thrombosis secondary to allergic fungal sinusitis. Rhinology 2009;47:105-108.

[38] Naesens R, Ronsyn M, Druwe P, Denis O, Ieven M, Jeurissen A. Central nervous system invasion by community-acquired methicillin-resistant Staphylococcus aureus. J Med Microbiol 2009;58(Pt 9):1247-1251.

[39] Ito E, Saito K, Nagatani T, Teranishi M, Aimi Y, Wakabayashi T. Cavernous sinus thrombophlebitis caused by porphyromonas gingivalis with abscess formation extending to the orbital cavity. Case report. Neurol Med Chir 2009;49:370-373.

[40] Raza S, Mahmood K, Hakeem A, Polsky S, Haemel A, Rai S, Ali Baig M. Adverse clinical sequelae after skin branding: a case series. J Med Case Rep 2009;3:25.

[41] Nakamura S, Kawamata T, Kobayashi T, Hori T. Clival inflammation with cavernous sinus thrombophlebitis and orbital subperiosteal abscess-case report. Neurol Med Chir 2010;50:168-171.

[42] Nog R, Anyimadu H, Schliep T, Alao O, Sivapalan V, Badshah C. The rising concern of community-acquired methicillin-resistant Staphylococcus aureus central nervous system infections: 2 case reports. Int J Infect Dis 2010;14: e393.

[43] Kim US, Kim JS, Kwon OK, Hwang JM. Complete visual recovery after mycotic aneurysm embolization complicated by cavernous sinus thrombophlebitis. Korean $J$ Ophthalmol 2010;24:322-324.

[44] Visvanathan V, Uppal S, Prowse S. Ocular manifestations of cavernous sinus thrombosis. BMJ Case Rep 2010; doi:10.1136/bcr.08.2009.2225

[45] Chick RS, Glisson JK, Pierce S. Bilateral cavernous sinus thrombosis following community-acquired methicillinresistant Staphylococcus aureus infection: a case report and review of the literature. J Miss State Med Assoc 2010;51:317-320.

[46] Kiddee W, Preechawai P, Hirunpat S. Bilateral Septic cavernous sinus thrombosis following the masticator and parapharyngeal space infection from the odontogenic origin: a case report. J Med Assoc Thai 2010;93:1107-1111.

[47] Alves CAF, Ribeiro O Jr., Ribeiro ANC. Cavernous sinus thrombosis in a patient with facial myiasis. Quintessence International 2010;41:e72-e74.

[48] Barahimi B, Murchison AP, Bilyk JR. Forget me not. Surv Ophthalmol 2010;55:467-480.

[49] Colbert S, Cameron M, Williams J. Septic thrombosis of the cavernous sinus and dental infection. $\mathrm{Br} J$ Oral Maxillofac Surg 2011;49:e25-e26.

[50] Imholz B, Becker M, Lombardi T, Scolozzi P. Septic thrombosis of the cavernous sinus secondary to a Streptococcus milleri oral infection. Dentomaxillofac Radiol 2012;41:525-528.

[51] Desa V, Green R. Cavernous sinus thrombosis: current therapy. J Oral Maxillofac Surg 2012;70:2085-2091.
[52] Songu M, Can N, Onal K, Arslanoglu S, Erdogan N, Kopar A, Ciger E. Staphylococcus aureus cavernous sinus thrombosis mimicking complicated fungal sinusitis. Ear Nose Throat J 2012;91:E26-E30.

[53] Suntrup S, Kemmling A, Dziewas R, Niederstadt T, Ritter MA. Septic cavernous sinus thrombosis complicated by occlusion of the internal carotid artery and multiple embolic strokes after surgery of an anorectal abscess: a clinical chameleon. Neurologist 2012;18:310-312.

[54] Horowitz A, Spendel D, Kraut R, Orentlicher G. Cavernous sinus thrombosis as a result of a fungal infection: a case report. J Oral Maxillofac Surg 2013;71:1899 e1-e5.

[55] Rajmane VS, Rajmane ST, Patil VC, Patil AB, Mohite ST. Maxillary rhinosinusitis due to Fusarium species leading to cavernous sinus thrombosis. J Mycol Med 2013;23:53-56.

[56] Sáiz A, Santamarta E, Meilán A, Vega P, López F. Bilateral cavernous sinus thromboses secondary to Streptococcus milleri: an uncommon and potentially lethal disease. Neuroradiology 2013;55:1455-1511.

[57] Sethi P, Jones ST, Valenzuela AA. Septic cavernous sinus thrombosis with diffuse spread leading to cerebral ischemia. Orbit 2013;32:330-332.

[58] Kay J, Smith DT. Clinical vignettes "tips" for avoiding cavernous sinus thrombosis. J Gen Intern Med 2013;28: S248.

[59] Clarke M, Enuh H, Saverimuttu J, Nfonoyim J. Streptococcus group C meningitis with cavernous sinus thrombosis. Infect Drug Resist 2013;6:79-81.

[60] Kapoor S. Cavernous sinus syndrome: a rare complication of neurosyphilis. Intern Med J 2014;44:428-429.

[61] Alian S, Taghipour M, Sharifian R, Fereydouni MA. Cavernous sinus thrombosis syndrome and brainstem involvement in patient with leptospirosis: two rare complications of leptospirosis. J Res Med Sci 2014;19:907-910.

[62] Sakaida H, Kobayashi M, Ito A, Takeuchi K. Cavernous sinus thrombosis: linking a swollen red eye and headache. Lancet 2014;384:928.

[63] Brown-Walker K, Roberts-Atwater B. An unusual case of neurovascular complications from septic cavernous sinus thrombosis. Am J Phys Med Rehabil 2014:e57-e58.

[64] Dinaker M, Sharabu C, Kattula SRST, Kommalapati V. A case of cavernous sinus thrombosis with meningitis caused by community acquired methicillin resistant Staphylococcus aureus. I Assoc Physicians India 2014;62:436-438.

[65] Nair D, Moore S, Bhatnagar D. A mass of mucor. J Gen Intern Med 2014:S277.

[66] Leo QJ, Bolger DT Jr. Septic cavernous sinus thrombosis due to Campylobacter rectus infection. BMJ Case Rep 2014 doi:10.1136/bcr-2013-203351.

[67] Chi TH, Chen HS, Yuan CH, Su FM. Acute fulminant invasive fungal sinusitis with cavernous sinus syndrome. $J$ Coll Physicians Surg Pak 2014;24:S240-S242.

[68] Lize F, Verillaud B, Vironneau P, Blancal JP, Guichard JP, Kania R, Herman P. Septic cavernous sinus thrombosis secondary to acute bacterial sinusitis: a retrospective study of seven cases. Am J Rhinol Allergy 2015;29:e7-e12. 